\title{
Incidence of sudden unexpected death in epilepsy in community-based cohort in China
}

Yan $\mathrm{Ge}^{1}$,Ding Ding ${ }^{2}$, Qing Zhang ${ }^{3}$, Bin Yang ${ }^{4}$, Taiping Wang ${ }^{5}$, Beixu $\mathrm{Li}^{6}$, Jie Wang ${ }^{7}$, Jianfeng Luo ${ }^{8}$, Patrick Kwan ${ }^{9}$,Wenzhi Wang ${ }^{10}$, Zhen Hong ${ }^{2}$, Josemir W. Sander ${ }^{11,12}$

1. Department of Neurology, Huashan Hospital, Fudan University, Shanghai, China (Yan Ge)

2. Institute of Neurology, WHO Collaborating Center for Research and Training in Neurosciences, Huashan Hospital, Fudan University, Shanghai, China (Ding Ding, Zhen Hong)

3. Department of Neurology, Ningxia Medical University Affiliated Hospital, Yinchuan, China (Qing Zhang)

4. Jiaozuo People's Hospital, Jiaozuo, Henan, China (Bin Yang)

5. Jincheng Emergency Center, Shanxi Province, China (Taiping Wang)

6. Department of Forensic Medicine, School of Basic Medicine, Fudan University, Shanghai, China (Beixu Li)

7. Department of Human Anatomy and Histoembryology, School of Basic Medicine, Fudan University, Shanghai, China (Jie Wang)

8. Department of Biostatistics, School of Public Health, Fudan University, Shanghai, China (Jianfeng Luo)

9. Department of Medicine and Neurology, University of Melbourne\&Royal Melbourne Hospital, Melbourne, Victoria, Australia (Patrick Kwan)

10. Beijing Neurosurgical Institute, Capital Medical University, Beijing, China (Wenzhi Wang)

11. NIHR University College London Hospitals Biomedical Research Centre, UCL Institute of Neurology, Queen Square, London WC1N 3BG (Josemir W. Sander)

12. Stichting Epilepsie Instellingen Nederland (SEIN), Achterweg 5 Heemstede 2103 SW, the Netherlands (Josemir W. Sander)

Correspondence Authors:

Ding Ding

Huashan Hospital, 12 Middle Wulumuqi Rd., Shanghai 200040, China

Phone: +86 2152888158

FAX: +862162481930

dingding@huashan.org.cn

Ley Sander 
NIHR University College London Hospitals Biomedical Research Centre, UCL

Institute of Neurology, Queen Square, London WC1N 3BG, UK

Phone: +44 (0) 2034488612

FAX: +44 (0) 2034488615

1.sander@ucl.ac.uk 


\section{Abstract}

Objective: Sudden unexpected death in epilepsy (SUDEP) is associated to the high premature mortality observed amongst people with epilepsy. It is, however, considered a rare event in China, probably due to lack of awareness and limitation of studies in the country. We aimed to provide some initial estimation of the burden of SUDEP in China.

Methods: We established a large Chinese community-based cohort of people with epilepsy between January 2010 and December 2011. For any participant who died during follow up, detailed information on cause of death was obtained using a specifically designed Verbal Autopsy Questionnaire. All cases were reviewed by a multidisciplinary expert panel and re-investigated if necessary. SUDEP incidence rates were estimated and case details provided.

Results: The cohort consisted of 1,562 people with epilepsy and during a median 5 years follow-up, 72 deaths were reported. The all-causes death incidence was 11.23(95\%CI 8.86-14.07) per 1,000 person-years. Fifteen of the deceased died suddenly and unexpectedly in a reasonable state of health in the week preceding death. We recorded detailed information of these 15 deaths. Thirteen were considered to be probable SUDEP and two possible SUDEP. The incidence of probable SUDEP was 2.03(95\%CI 1.13-3.38) per 1,000 person-years and the incidence of all suspected (probable and possible) SUDEP was 2.34(95\%CI 1.36-3.77) per 1,000 person-years. Significance: The incidence of SUDEP was relatively high among Chinese people with epilepsy when compared with previous community-based studies from high-income countries. The burden of SUDEP in China requires assessments.

Key words: Premature mortality, SUDEP, Verbal Autopsy, Seizure 


\section{Introduction}

Sudden unexpected death in epilepsy (SUDEP) is associated to the premature mortality seen amongst people with epilepsy. In western countries, the incidence of SUDEP varies with the sample population, increasing from 0.35 to 2.3 in community samples to 1.1 to 5.9 in epilepsy clinics and between 6.3 and 9.3 in participants of epilepsy surgery programs ${ }^{[1]}$. One long term study reported that in a cohort of people with epilepsy followed for over 30 years, SUDEP accounted for $30 \%$ of all death ${ }^{[2]}$.

There have been some Chinese case reports of SUDEP with autopsy but overall studies of SUDEP are still limited in China where there are over 9 million people with epilepsy ${ }^{[3]}$.Only two prospective mortality studies have been reported from China ${ }^{[4-5]}$; and they did not estimate SUDEP incidence making comparisons with reports from other countries difficult. The large variation in the proportional mortality ratios for $\operatorname{SUDEP}\left(14.7 \%^{[4]}\right.$ and $\left.1 \%{ }^{[5]}\right)$ between these two studies suggests some methodological shortcomings in the diagnosis of SUDEP. Autopsies are rarely acceptable in Asia and particularly in China and this compound the issue.

We carried out a study to estimate the incidence of SUDEP in a Chinese population using specifically designed instruments to overcome some of the shortages and to report detailed information about cases identified.

\section{Material and Methods}

\subsection{Study cohort with epilepsy}

Between January 2010 and December 2011, people with epilepsy were recruited from rural areas in the Chinese provinces of Henan, Shanxi, and Ningxia,, as a part of the "Validation of Clinical Assessment Tools for Population Genetic Studies of Epilepsy (1R21NS069223-01, NIH/NINSD)". People with epilepsy aged 2-80 years 
were eligible for inclusion, they were, however, excluded if: 1) they had non-epileptic attack disorder; 2) their seizure were related to alcohol or drug abuse; 3) their seizures resulted from progressive neurological or systemic disorders; 4) their adherence to their drug regime or seizure control couldn't be adequately assessed; 5) they were pregnant; 6) they or their guardians were unable to provide consent.

\subsection{Clinical assessment and data collection at baseline}

The baseline clinical assessment procedure was in two stages. In stage 1, trained village physicians used door-to-door interviews to identify individuals who were having seizures, who had at least one family member who had witnessed seizures and was familiar with their medical history. They recorded demographic details, clinical symptoms, birth and developmental history, family history, medical history, treatment history. In stage 2 , each person identified in stage 1 as having epilepsy went to the designated provincial epilepsy center and were reviewed by a neurologist and had the diagnosis confirmed or refuted. At this stage the neurologist also completed a full diagnostic questionnaire covering 1) demographics; 2) age of onset and seizure frequency; 3) full antiepileptic treatment history; 4) risk factors, such as history of CNS infections, brain injury, family history of epilepsy (in close relatives), abnormal birth history, stroke, and brain tumor; 5) seizure-associated medical history: history of status epilepticus and febrile seizures; 6) results of EEG and MRI/CT. We classified seizures as generalized, focal or unknown according to ILAE guidelines ${ }^{[6]}$. The putative etiology of epilepsy was classified as genetic, structural/metabolic or unknown. A panel of epilepsy-experienced neurologists (PK, JWS, and ZH) reviewed diagnoses, and any discrepancies were resolved by consensus. 


\subsection{Follow-up procedure}

Two follow-up visits were conducted during March 2013 to October 2014, and October 2015 to March 2016. The local physician interviewed each participant at their home. The interview was conducted via mobile phone or by interviewing family members for those who were offsite. The interview covered current clinical, treatments and survival status. Loss-to-follow-up was defined as those whose survival status could not be established during either follow-up.

\subsection{Verbal Autopsy Questionnaire}

For those who had died, death certificates were collected from the appropriate office. A specifically designed Verbal Autopsy Questionnaire (VAQ) was used (see supplement 1). Primary-care physicians asked relatives or local physicians for specific death-related questions as required by the VAQ including place and timing of death, body position when found, whether death was witnessed, whether a seizure preceded death or whether there was circumstantial evidence for a seizure before death (incontinence, bitten tongue), whether there was evidence or suspicion for suicide, whether there were injuries and whether the victim was in a reasonable state of health in the week prior to demise. A detailed description of death and the putative cause were also recorded.

\subsection{Confirmation of death causes and SUDEP}

All the VAQs were reviewed by an expert panel consisting of neurologists (YG, JWS), neuro-epidemiologist (DD) and forensic pathologists (BXL and JW). Inquiries were made in case of uncertainties or unclear records. YG visited study sites to collect further data to clarify doubts until the panel had sufficient information to attribute a 
putative cause of death for each case. These were attributed by consensus after consideration of all available information according to the International Classification of Diseases, 10th Edition (ICD-10) ${ }^{[7]}$. The "unknown" cause of death included those without any information. SUDEP was defined as sudden unexpected death in an individual with epilepsy with or without evidence of a seizure, and excluding documented status epilepticus, where postmortem examination does not reveal an anatomic or toxicological cause of death ${ }^{[8]}$, and classified ${ }^{[9]}$ as definite SUDEP, probable SUDEP (meets all criteria, but lacks postmortem data). The criteria for probable SUDEPwere:1) the victim had epilepsy; 2) the victim died unexpectedly while in a reasonable state of health; 3) the death occurred "suddenly" (in minutes), when known; 4) the death occurred during normal activities (e.g. in or around bed, at home, at work) and benign circumstances; 5) an obvious medical cause of death was not found. Criteria for possible SUDEP were: SUDEP cannot be ruled out, but there is insufficient evidence regarding the circumstances of the death and no postmortem report is available. Full postmortem and toxicological data are not available in rural China, so we attributed probable SUDEP where the victim died suddenly and unexpectedly while in a reasonable state of health in the week prior to death and where there was no other plausible cause of death and foul play was ruled out.

\subsection{Standard protocol approvals, registrations, and patient consents}

The original study was approved by the joint Chinese University of Hong Kong-New Territories East Cluster Research Ethics Committee and the institutional review board of the Beijing Neurosurgical Institute in China. The follow-up exercise was approved by the Medical Ethics Committee of Fudan University affiliated Huashan Hospital, Shanghai, China. Written informed consent was obtained from all 
participants and/or their legally acceptable guardians.

\subsection{Statistical analysis}

Continuous variables are expressed as mean (SD), or median (minimum, maximum), and categorical variables as counts and frequencies (\%).Student t-test was used to compare continuous variables. Chi-square test or Kruskal-Wallis test was used for comparing categorical variables.

Incidence rates of all-cause mortality and SUDEP cases were estimated as the number of incident cases occurring during the follow-up period divided by the cumulative follow-up period of all subjects, described as "per 1000 person-years", and results presented with 95\% confidence intervals (CIs).Cox proportional hazards regression model was used to estimate the relative risk (RR) with $95 \%$ CIs of all-cause mortality and SUDEP, within the different subgroups of gender, age of onset, age at the baseline, seizure type, treatment, and remission. Individuals were censored if they were lost to follow-up.

All p-values and 95\%CI were estimated in a two-tailed fashion. Differences were considered to be statistically significant at $p<0.05$. Data were analyzed using SPSS 16.0 (SPSS Inc., IL, USA).

\section{Results}

\subsection{Characteristics of subjects at the baseline and follow-up}

A total of 1,562 people were enrolled (baseline clinical and demographic characteristics provided in Table 1. Sixty percent were on anti-epileptic drug (AED) monotherapy and only $20 \%$ were in one-year remission when enrolled. A study flowchart is provided in Fig 1. We were unable to determine survival status of 105 
people in both two follow-ups thus the lost-to-follow up rate was $6.7 \%$. No significant differences were found for baseline characteristics between those who were followed and those lost to follow-up (Table 1).

We also compared the baseline characteristics between survivors and those who died. People who died were older (median age: 47.5 years and age of onset: 20 years) than those who survived and more likely to be males (72.2\%) and this was significant $(\mathrm{p}=0.014)$. The proportion of those who were in one-year remission at baseline was significantly lower in those who died than in those who survived (11.1\% vs. $20.7 \%$, $\mathrm{p}=0.045)$.

\subsection{Mortality outcome during the follow-up}

We identified 72 deaths during a median of 57 months of follow-up. The incidence of all-cause death was $11.23(95 \%$ CI 8.86-14.07) per 1,000 person-years (table 2). The median age at deaths was 47.5(11-90) years. The incidence of all-cause death in different subgroups are given in Table 2. The risk of death among men was $86 \%$ [RR 1.86 (95\% CI 1.11-3.12)] higher than in women. The mortality risk increased with age and age of onset. The RR was 1.22 (95\% CI 0.49-3.05) for those whose age was 18 to 60 years old, and was $4.31(95 \%$ CI 1.60-11.62) for those whose age was over 60 years old (both compared with those aged less than 18 years). The RR was 1.70 (95\% CI 1.05-2.75) for those with age of onset was 18 to 60 years old, and RR was 5.24 (95\% CI 1.85-14.82) for those with age of onset over 60 years old, compared with those whose onset was at less than 18 years. Individuals who had frequent seizures had a higher risk of death ([RR 2.40(95\% CI 1.09-5.27)] in those who had 1 to 4 seizures per month, and [RR 2.41(95\% CI 1.03-5.64)] in those who had over 4 seizures per month, compared with those who were in one year remission 
at baseline).

As shown in Figure 1, the most common cause of death was accidental (30.6\%) (8 drowning, 4 traffic accident, 4 poisoning, 3 falling and 3 other accidents). Fifteen deaths $(20.8 \%)$ were sudden and unexpected. and were classified as suspected SUDEP cases.

\subsection{Characteristics of SUDEP cases}

Detailed information of the suspected SUDEP cases is provided in Table 3. Most $(10 / 15)$ were male. All had convulsions either focal seizures with secondary generalization (8/15) or generalized tonic-clonic seizures (7/15). Age of death ranged from 20-90 years and 10/15 died before the age of 60. Five deaths were witnessed, and a seizure before death was reported in four ( 3 had confirmed and 1 had a suspected seizure). Thirteen of the 15 died in the bedroom. Only two were found dead in a prone position. Seizure numbers in the year before death was available in 14/15 and none of them had been seizure free.

We regarded 13 of these suspected SUDEP cases as probable SUDEP and 2 as possible SUDEP (they were 80 and 90 years old and without sufficient evidence of a preceding seizure).

\subsection{Incidence of SUDEP}

The incidence of probable SUDEP was 2.03(95\%CI 1.13-3.38) per 1,000 person-years, and the incidence of probable and possible SUDEP was 2.34(95\%CI 1.36-3.77) per 1,000 person-years. We report SUDEP incidence in different subgroups in Table 2. SUDEP incidence and RRs were explored in males, age and onset age over 60 years old, genetic/unknown etiology, focal with secondary generalized seizure type, 
non AED treatment, and more seizure frequency, but none was found to be statistically significant.

\section{Discussion}

In this large prospective community-based Chinese study, we identified cases of SUDEP and estimated a relatively high incidence for SUDEP. Studies from high-income countries suggest that SUDEP is responsible for up to $30 \%{ }^{[2,10-12]}$ of deaths and its leading cause of epilepsy-related death ${ }^{[2]}$. There is little data concerning SUDEP in China as only two studies have reported the proportional mortality ratios of SUDEP in epidemiological studies. A study from West China reported15 probable SUDEP cases $\left(14.7 \%\right.$ ) during a 2-year follow-up period ${ }^{[4]}$. A further study identified only two probable SUDEP cases $(1 \%)$ during the over 6-year follow-up period ${ }^{[5]}$. In the current study, we found $18 \%$ of the deceased were possible SUDEP during a 5-year follow-up period. The variance between these studies suggests difficulties in diagnosing SUDEP accurately in resource-poor settings, especially where post-mortem examination are rare and usually unacceptable in traditional cultures such as in China.

In the current study, we attempted to improve SUDEP diagnosis through several methods. Firstly, we designed the VAQ based on widely-used SUDEP criteria ${ }^{[9]}$. Secondly, we did not accept the putative cause of death as in the death certificate. SUDEP might be easily misdiagnosed as heart attack, stroke or other causes of sudden death by unfamiliar reporters. Our expert panel, who were all familiar with SUDEP, reviewed all the VAQs, paying particular attention to those in whom the reported or certified cause of death was cardiac, cerebral vascular, unknown or sudden. If data was not sufficient to support the reported cause of death, further inquiries were made. 
Thirdly, we established a multi-disciplinary panel to attribute causes including two experienced forensic pathologists and their input helped to establish more accurate putative causes. Fourthly, we report detailed information of all suspected SUDEP cases to provide an overall impression of the cases in our study.

We identified 15 sudden, unexpected deaths, and 13 of these cases were regarded as probable SUDEP and 2 as possible. These 13 probable cases meet the criteria without autopsy. Two cases were classified to possible SUDEP as they were older (>79years), which increases the risk for other causes of sudden death (cardiac attack, pulmonary embolus). In most previous studies, the age of SUDEP cases were mainly younger than 60 years ${ }^{[2,12-20]}$, and the incidence in the elderly was relatively low. SUDEP might, however, be under-diagnosed in older people in whom sudden death might be attributed to other causes without careful investigation of alternatives ${ }^{[1]}$. Many previous studies might also not have been able to investigate SUDEP in elderly people as often these studies focus on childhood-onset epilepsy and most participants not old enough. In our study, 144 participant were older than 60 years and SUDEP incidence was [7.48(95\% CI 2.38-18.04)] much higher than in those younger than 60([2.10(95\%CI 1.11-3.66)]. Due to longer life-expectancy, the proportion of elderly may increase further and this may also be reflected in future SUDEP studies.

The incidence of all suspected (probable and possible) SUDEP was 2.34(95\%CI 1.36-3.77) per 1,000 person-years, which is out of the range of the incidence $(0.35-2.1$ per 1,000 person-years) from community-based studies from high-income countries (Table 4).This may be the result of the population studied and definitions used (we included probable and possible cases in the incidence estimation; in most studies, only definite and probable cases are included). When focused on the incidence of probable SUDEP, the incidence in the current study (2.03(95\%CI 1.13-3.38) per 1,000 
person-years) falls in the range of previous reports $(0.35-2.1$ per 1,000 person-years $)$

(Table 4).

Prone position was found in $42 \%-81 \%$ of SUDEP cases in previous reports in western population $^{[21]}$. However, we found only 2 (13\%) of SUDEP cases in prone position in our study. Larger-sampled studies are needed to clarify the association between prone position and SUDEP in Chinese people with epilepsy.

Baseline characters of the participants in our study were comparable to the previous multi-centered cohort in mainland China ${ }^{[5]}$. There was no evidence for major selection bias in the current study.

Post-mortem examinations are rare in mainland China, especially in rural areas and this poses difficulties in investigating SUDEP. Without an autopsy, we were not able to confirm definite SUDEP cases and causes could only be putative. This is a major limitation. Our purpose, however, was to investigate the presence of SUDEP in China and to provide an initial incidence estimation as accurately as possible, within a known background of a lack of autopsies. In a UK study $40 \%$ of subjects who died suddenly and might otherwise have had a diagnosis of SUDEP, were shown at post-mortem to have probable cardiovascular causes of death ${ }^{[10]}$.So we might have overestimated SUDEP incidence.

\section{Conclusion}

There are over nine million people with epilepsy in China. Our results suggest that yearly SUDEP may kill over 20,000 people. Further prospective Chinese studies with larger sample size and longer follow-up periods are urgently needed to examine risk and protective factors in order to seek proper interventions to reduce the burden of SUDEP. 


\section{Acknowledgments}

We thank all the village physicians for their hard field work of follow-up, and all participants for their cooperation. JWS is based at UCLH/UCL Comprehensive Biomedical Research Centre, which receives a proportion of funding from the UK Department of Health's National Institute for Health Research Biomedical Research Centers funding scheme. He receives support from the Dr. Marvin Weil Epilepsy Research Fund and UK Epilepsy Society. Study was funded by National Nature Science Foundation of China(81271443), Key Research Project of the Ministry of Science and Technology of China.(Grant No. 2016YFC0904400), and NIH/NINDS grant (1R21NS069223-01).

\section{Author Disclosures}

YG, DD, BY, QZ, TW, WW, BL, JW, JL, PK and ZH report no disclosures; JWS has received research funding from Eisai, GSK and UCB, personal fees from Eisai, UCB Lundbeck and Teva, outside the submitted work.

\section{Ethical Publication Statement}

We confirm that we have read the Journals position on issues involved in ethical publication and affirm that this report is consistent with those guidelines.

\section{Reference}

[1] Devinsky O, Hesdorffer DC, Thurman DJ, Lhatoo S, Richerson G. Sudden unexpected death in epilepsy: epidemiology, mechanisms, and prevention. Lancet 
Neurol 2016;15: 1075-88.

[2] Sillanpaa M, Shinnar S. Long-term mortality in childhood-onset epilepsy. N Engl J Med 2010;363: 2522-9.

[3] Wang W, Wu J, Dai X, Ma G, Yang B, Wang T, Yuan C, Ding D, Hong Z, Kwan P, Bell GS, Prilipko LL, de Boer HM, Sander JW. Global campaign against epilepsy: assessment of a demonstration project in rural China. Bull World Health Organ 2008;86: 964-9.

[4] Mu J, Liu L, Zhang Q, Si Y, Hu J, Fang J, Gao Y, He J, Li S, Wang W, Wu J, Sander JW, Zhou D. Causes of death among people with convulsive epilepsy in rural West China: a prospective study. Neurology 2011;77: 132-7.

[5] Ding D, Wang W, Wu J, Yang H, Li S, Dai X, Yang B, Wang T, Yuan C, Ma G, Bell GS, Kwan P, de Boer HM, Hong Z, Sander JW. Premature mortality risk in people with convulsive epilepsy: long follow-up of a cohort in rural China. Epilepsia 2013;54: 512-7.

[6] Berg AT, Berkovic SF, Brodie MJ, Buchhalter J, Cross JH, van Emde Boas W, Engel J, French J, Glauser TA, Mathern GW, Moshe SL, Nordli D, Plouin P, Scheffer IE. Revised terminology and concepts for organization of seizures and epilepsies: report of the ILAE Commission on Classification and Terminology, 2005-2009. Epilepsia 2010;51: 676-85.

[7] ICD-10 International statistical classification of diseases and related health problems 10th revision Volume 2 Instruction manual Fifth edition 2016, http://apps.who.int/classifications/icd10/browse/Content/statichtml/ICD10Volume2_e n_2016.pdf Accessed February 23, 2017. 
[8] Nashef L. Sudden unexpected death in epilepsy: terminology and definitions. Epilepsia 1997;38: S6-8.

[9] Annegers JF. United States perspective on definitions and classifications. Epilepsia 1997;38: S9-12.

[10]Novy J, Belluzzo M, Caboclo LO, Catarino CB, Yogarajah M, Martinian L, Peacock JL, Bell GS, Koepp MJ, Thom M, Sander JW, Sisodiya SM. The lifelong course of chronic epilepsy: the Chalfont experience. Brain 2013;136: 3187-99.

[11] Nickels KC, Grossardt BR, Wirrell EC. Epilepsy-related mortality is low in children: a 30-year population-based study in Olmsted County, MN. Epilepsia 2012;53: 2164-71.

[12]Walczak TS, Leppik IE, D'Amelio M, Rarick J, So E, Ahman P, Ruggles K, Cascino GD, Annegers JF, Hauser WA. Incidence and risk factors in sudden unexpected death in epilepsy: a prospective cohort study. Neurology 2001;56: 519-25. [13]Weber P, Bubl R, Blauenstein U, Tillmann BU, Lutschg J. Sudden unexplained death in children with epilepsy: a cohort study with an eighteen-year follow-up. Acta Paediatr 2005;94: 564-7.

[14]Langan Y, Nolan N, Hutchinson M. The incidence of sudden unexpected death in epilepsy (SUDEP) in South Dublin and Wicklow. Seizure 1998;7: 355-8.

[15]Ficker DM, So EL, Shen WK, Annegers JF, O'Brien PC, Cascino GD, Belau PG. Population-based study of the incidence of sudden unexplained death in epilepsy. Neurology 1998;51: 1270-4.

[16]Nashef L, Fish DR, Sander JW, Shorvon SD. Incidence of sudden unexpected 
death in an adult outpatient cohort with epilepsy at a tertiary referral centre. J Neurol Neurosurg Psychiatry 1995;58: 462-4.

[17]Gronborg S, Uldall P. Mortality and causes of death in children referred to a tertiary epilepsy center. Eur J Paediatr Neurol 2014;18: 66-71.

[18]Terra VC, Scorza FA, Arida RM, Fernandes RM, Wichert-Ana L, Machado HR, Sakamoto AC. Mortality in children with severe epilepsy: 10 years of follow-up. Arq Neuropsiquiatr 2011;69: 766-9.

[19]Ryvlin P, Nashef L, Lhatoo SD, Bateman LM, Bird J, Bleasel A, Boon P, Crespel A, Dworetzky BA, Hogenhaven H, Lerche H, Maillard L, Malter MP, Marchal C, Murthy JM, Nitsche M, Pataraia E, Rabben T, Rheims S, Sadzot B, Schulze-Bonhage A, Seyal M, So EL, Spitz M, Szucs A, Tan M, Tao JX, Tomson T. Incidence and mechanisms of cardiorespiratory arrests in epilepsy monitoring units (MORTEMUS): a retrospective study. Lancet Neurol 2013;12: 966-77.

[20]Holst AG, Winkel BG, Risgaard B, Nielsen JB, Rasmussen PV, Haunso S, Sabers A, Uldall P, Tfelt-Hansen J. Epilepsy and risk of death and sudden unexpected death in the young: a nationwide study. Epilepsia 2013;54: 1613-20.

[21]Liebenthal JA, Wu S, Rose S, Ebersole JS, Tao JX. Association of prone position with sudden unexpected death in epilepsy. Neurology 2015;84: 703-9.

[22] Tennis P, Cole TB, Annegers JF, Leestma JE, McNutt M, Rajput A. Cohort study of incidence of sudden unexplained death in persons with seizure disorder treated with antiepileptic drugs in Saskatchewan, Canada. Epilepsia 1995;36: 29-36.

[23]Lhatoo SD, Langan Y, MacDonald BK, Zeidan S, Sander JW. Sudden unexpected 
death: a rare event in a large community based prospective cohort with newly diagnosed epilepsy and high remission rates. J Neurol Neurosurg Psychiatry 1999;66: 692-3. 
Table 1 Demographics and clinical characteristics of people with epilepsy in the original cohort, those lost-to-follow up, and those followed up

\begin{tabular}{|c|c|c|c|c|c|}
\hline \multirow[b]{3}{*}{ Baseline characteristics } & \multirow{3}{*}{$\begin{array}{l}\text { All people with } \\
\text { epilepsy in the } \\
\text { initial cohort } \\
\mathrm{n}=1,562\end{array}$} & \multirow{3}{*}{$\begin{array}{l}\text { Lost to follow-up* } \\
\mathrm{n}=105\end{array}$} & \multicolumn{2}{|c|}{ Followed up } & \multirow{3}{*}{ p-value } \\
\hline & & & Alive & Deceased & \\
\hline & & & $\mathrm{n}=1,385$ & $\mathrm{n}=72$ & \\
\hline Age, year, median(range) & $38(2-88)$ & $38(4-78)$ & $38(2-83)$ & $47.5(10-88)$ & 0.001 \\
\hline Age of onset, year, median(range) & $14(<1-78)$ & $13(<1-63)$ & $14(<1-77)$ & $20(1-78)$ & 0.014 \\
\hline \multicolumn{6}{|l|}{ Gender } \\
\hline Male, $\mathrm{n}(\%)$ & $904(57.9)$ & $54(54.1 \%)$ & $798(57.6)$ & $52(72.2)$ & \multirow[t]{2}{*}{0.014} \\
\hline Female, n $(\%)$ & $658(42.1)$ & $51(48.6 \%)$ & $587(42.4)$ & $20(27.8)$ & \\
\hline \multicolumn{6}{|l|}{ Etiology } \\
\hline Genetic/Unknown, n (\%) & $1,137(72.8)$ & $72(68.6 \%)$ & $1016(73.4)$ & $48(66.7)$ & \multirow[t]{2}{*}{0.212} \\
\hline Structural/Metabolic, n (\%) & $425(27.2)$ & $33(31.4 \%)$ & $369(26.6)$ & $24(33.3)$ & \\
\hline \multicolumn{6}{|l|}{ Seizure type } \\
\hline $\begin{array}{l}\text { Focal without secondary } \\
\text { generalized, } \mathrm{n}(\%)\end{array}$ & 103(6.6) & $9(8.6)$ & $89(6.4)$ & $5(6.9 \%)$ & \multirow{4}{*}{0.829} \\
\hline $\begin{array}{l}\text { Focal with secondary } \\
\text { generalized, n }(\%)\end{array}$ & $776(49.7)$ & $61(58.1)$ & $677(48.9)$ & $38(52.8)$ & \\
\hline Generalized, n (\%) & $675(43.2)$ & $35(33.3)$ & $611(44.1)$ & $29(40.3)$ & \\
\hline Unknown & $8(0.5)$ & $0(0)$ & $8(0.6)$ & $0(0)$ & \\
\hline \multicolumn{6}{|l|}{ AED treatment } \\
\hline None & $245(15.7)$ & $16(15.4)$ & $219(15.8)$ & $10(14.1)$ & \\
\hline
\end{tabular}




\begin{tabular}{|c|c|c|c|c|c|}
\hline Monotherapy & $923(59.2)$ & $57(54.8)$ & $823(59.5)$ & $43(60.6)$ & 0.926 \\
\hline Polytherapy & $391(25.1)$ & $31(29.8)$ & $342(24.7)$ & $18(25.4)$ & \\
\hline \multicolumn{6}{|l|}{$\begin{array}{l}\text { Seizure frequency within one year } \\
\text { before baseline }\end{array}$} \\
\hline Terminal one year remission, $\mathrm{n}(\%)$ & $310(20.2)$ & $21(21.0)$ & $281(20.7)$ & $8(11.1)$ & \\
\hline$<1 /$ month & $520(34.0)$ & $30(30.0)$ & $470(34.6)$ & $20(27.8)$ & 0.045 \\
\hline $1-4 /$ month & $447(29.2)$ & $32(32.0)$ & $387(28.5)$ & $28(38.9)$ & \\
\hline$>4 /$ month & $254(16.6)$ & $17(17.0)$ & $221(16.3)$ & $16(22.2)$ & \\
\hline
\end{tabular}

* No significant differences were found for baseline characteristics between those who were followed and those lost to follow-up AED: Anti-epileptic drug 
Table 2 Incidence of all-cause death and SUDEP in different subgroup

\begin{tabular}{|c|c|c|c|c|c|c|c|}
\hline & & All-cause mortality & & Probable SUDEP & & $\begin{array}{c}\text { Probable and } \\
\text { possible SUDEP }\end{array}$ & \\
\hline & $\begin{array}{l}\text { Person-yrs } \\
\text { of } \\
\text { follow-up }\end{array}$ & $\begin{array}{c}\text { incidence } / 1,000 \\
\text { person-years }(95 \% \\
\text { CI })\end{array}$ & $\mathrm{RR}(95 \% \mathrm{CI})$ & $\begin{array}{c}\text { incidence } / 1,000 \\
\text { person-years }(95 \% \\
\text { CI) }\end{array}$ & $\mathrm{RR}(95 \% \mathrm{CI})$ & $\begin{array}{c}\text { incidence } / 1,000 \\
\text { person-years }(95 \% \\
\mathrm{CI})\end{array}$ & $\mathrm{RR}(95 \% \mathrm{CI})$ \\
\hline Total & 6409 & $11.23(8.86-14.07)$ & & $2.03(1.13-3.38)$ & & $2.34(1.36-3.77)$ & \\
\hline \multicolumn{8}{|l|}{ Gender } \\
\hline Female & 2676 & 7.47(4.69-11.34) & 1 & $1.12(0.29-3.05)$ & 1 & $1.49(0.47-3.61)$ & 1 \\
\hline Male & 3733 & $13.93(10.51-18.13)$ & $1.86(1.11-3.12)$ & $2.68(1.36-4.78)$ & $2.39(0.66-8.68)$ & $2.95(1.55-5.12)$ & $1.97(0.63-6.19)$ \\
\hline \multicolumn{8}{|l|}{ Onset age } \\
\hline$<18$ & 3833 & $8.35(5.35-11.65)$ & 1 & $1.83(0.80-3.61)$ & 1 & $1.83(0.80-3.61)$ & 1 \\
\hline $18-60$ & 2463 & $14.22(10.06-19.55)$ & $1.70(1.05-2.75)$ & $2.44(0.99-5.07)$ & $1.35(0.45-4.01)$ & $2.84(1.24-5.62)$ & $1.56(0.55-4.47)$ \\
\hline$>60$ & 90 & $44.44(14.12-107.20)$ & $5.24(1.85-14.82)$ & $\mathrm{NA}$ & & $11.10(0.56-54.80)$ & $6.46(0.79-52.57)$ \\
\hline \multicolumn{8}{|l|}{ Age at baseline } \\
\hline$<18$ & 648 & $7.72(2.83-17.10)$ & 1 & NA & & NA & \\
\hline $18-60$ & 5226 & $9.38(7.01-12.29)$ & $1.22(0.49-3.05)$ & $2.10(1.11-3.66)$ & 1 & $2.10(1.11-3.66)$ & 1 \\
\hline$>60$ & 535 & $34.35(21.00-53.24)$ & $4.31(1.60-11.62)$ & $3.74(0.63-12.35)$ & $1.78(0.27-7.14)$ & $7.48(2.38-18.04)$ & $3.55(0.98-10.81)$ \\
\hline \multicolumn{8}{|l|}{ Etiology } \\
\hline Structural/Metabolic & 1708 & $14.05(9.21-20.59)$ & 1 & $1.17(0.20-3.87)$ & 1 & $1.76(0.45-4.78)$ & 1 \\
\hline Genetic/Unknown & 4701 & $10.21(7.61-13.42)$ & $0.73(0.45-1.19)$ & $2.34(1.23-4.07)$ & $1.98(0.44-8.93)$ & $2.55(1.38-4.34)$ & $1.44(0.41-5.11)$ \\
\hline \multicolumn{8}{|l|}{ Seizure type } \\
\hline Focal without & 420 & $11.91(4.36-26.40)$ & 1 & NA & & NA & \\
\hline
\end{tabular}


secondary

generalized

Generalized

Focal with secondary

generalized

AED treatment

None
Monotherapy
Polytherapy

Seizure frequency

within one year before

baseline

Terminal one year

remission at baseline

$<1 /$ month

1-4/month

$>4 /$ month

$\begin{array}{ccc}2814 & 9.95(6.74-14.18) & 0.87(0.34-2.34) \\ 3137 & 12.29(8.86-16.63) & 1.01(0.40-2.57) \\ & & \\ 973 & 10.29(5.23-18.34) & 1 \\ 3844 & 11.19(8.20-14.93) & 1.10(0.55-2.20) \\ 1585 & 11.36(6.94-17.60) & 1.11(0.51-2.41)\end{array}$

2.13(0.86-4.42)

\section{1}

2.21(0.96-4.36)

1.04(0.34-3.28)

$2.13(0.86-4.42)$

2.84(1.38-5.20)

1

1.33(0.47-4.02)

$\begin{array}{ccc}3.09(0.79-8.40) & 1 & 4.12(1.31-9.93) \\ 2.08(0.97-3.95) & 0.66(0.18-2.49) & 2.34(1.14-4.30) \\ 0.63(0.03-3.11) & 0.20(0.02-1.93) & 0.63(0.03-3.11)\end{array}$

1

0.56(0.17-1.82)

$0.15(0.02-1.35)$

SUDEP: Sudden unexpected death in epilepsy; AED: Anti-epileptic drug; NA: not available; RR: relative risk; CI: confidence interval

$\begin{array}{ccccccc}1254 & 6.38(2.96-12.11) & 1 & 0.80(0.04-3.93) & 1 & 0.80(0.04-3.93) & 1 \\ 2162 & 9.25(5.81-14.03) & 1.46(0.64-3.31) & 0.93(0.16-3.06) & 1.15(0.10-12.65) & 1.38(0.35-3.78) & 1.72(0.18-16.58) \\ 1842 & 15.20(10.30-21.68) & 2.40(1.09-5.27) & 2.71(0.99-6.02) & 3.34(0.39-28.63) & 3.26(1.32-6.78) & 4.029(0.49-33.48) \\ 1039 & 15.40(9.12-24.47) & 2.41(1.03-5.64) & 4.81(1.76-10.67) & 5.94(0.69-50.86) & 4.81(1.76-10.67) & 5.955(0.70-50.97)\end{array}$


Table 3 Detailed information of suspected SUDEP cases

\begin{tabular}{|c|c|c|c|c|c|c|c|c|c|c|c|c|c|}
\hline $\begin{array}{l}\text { Pt. } \\
\text { NO. }\end{array}$ & $\begin{array}{c}\text { SUDEP } \\
\text { classification }\end{array}$ & $\begin{array}{c}\text { Reported } \\
\text { cause of } \\
\text { death }\end{array}$ & Gender & Seizure type & $\begin{array}{c}\text { number of } \\
\text { seizures within } \\
\text { the year before } \\
\text { death }\end{array}$ & $\begin{array}{l}\text { age at } \\
\text { onset } \\
\text { (years) }\end{array}$ & $\begin{array}{l}\text { age at } \\
\text { death } \\
\text { (years) }\end{array}$ & Place & Position & $\begin{array}{c}\text { Seizure } \\
\text { before } \\
\text { death }\end{array}$ & $\begin{array}{l}\text { Time of Death or } \\
\text { Found Death }\end{array}$ & Witnessed & Description \\
\hline 1 & probable & unknown & male & generalized & 24 & 15 & 20 & bedroom & latericumbent & suspected & 10 a.m. & no & $\begin{array}{l}\text { found dead at } 10 \text { a.m. with } \\
\text { foaming at the mouth }\end{array}$ \\
\hline 2 & probable & unknown & female & generalized & 10 & 14 & 22 & $\begin{array}{l}\text { living } \\
\text { room }\end{array}$ & latericumbent & no & 11 a.m. & yes & $\begin{array}{c}\text { Sudden loss of consciousness at } \\
11 \text { a.m., death confirmed at } \\
\text { doctor's arrival }\end{array}$ \\
\hline 3 & probable & seizure & male & $\begin{array}{l}\text { focal with } \\
\text { secondary } \\
\text { generalized }\end{array}$ & unknown & 4 & 23 & bedroom & unknown & confirmed & 1 a.m. & yes & $\begin{array}{l}\text { seizure during sleep, found dead } \\
\text { at } 1 \text { a.m. }\end{array}$ \\
\hline 4 & probable & unknown & male & generalized & 8 & 5 & 27 & bedroom & latericumbent & unknown & unknown & no & found dead at morning \\
\hline 5 & probable & seizure & female & $\begin{array}{l}\text { focal with } \\
\text { secondary } \\
\text { generalized }\end{array}$ & 11 & 3 & 28 & bedroom & prone & confirmed & unknown & yes & sudden death during a seizure \\
\hline 6 & probable & unknown & male & generalized & 4 & 21 & 35 & bedroom & supine & unknown & 10 a.m. & no & $\begin{array}{l}\text { Living with his family, found } \\
\text { dead at } 10 \text { a.m. }\end{array}$ \\
\hline 7 & probable & asphyxia & female & $\begin{array}{l}\text { focal with } \\
\text { secondary } \\
\text { generalized }\end{array}$ & 4 & 3 & 39 & bedroom & supine & suspected & 3 a.m. & no & $\begin{array}{l}\text { Living with family, found dead } \\
\text { at } 3 \text { a.m. with incontinence }\end{array}$ \\
\hline
\end{tabular}




\begin{tabular}{|c|c|c|c|c|c|c|c|c|c|c|c|c|c|}
\hline 8 & probable & $\begin{array}{c}\text { coronary } \\
\text { heart disease }\end{array}$ & female & generalized & 3 & 22 & 42 & bedroom & prone & unknown & 9 a.m. & no & $\begin{array}{l}\text { Work overnight till } 8 \text { a.m., } \\
\text { found dead at } 9 \text { a.m. by her } \\
\text { colleague. }\end{array}$ \\
\hline 9 & probable & unknown & male & generalized & 13 & 17 & 46 & bedroom & supine & suspected & 8 a.m. & no & $\begin{array}{l}\text { Living with his family, found } \\
\text { dead at } 8 \text { a.m. with incontinence } \\
\text { and damaged surroundings }\end{array}$ \\
\hline 10 & probable & unknown & male & $\begin{array}{l}\text { focal with } \\
\text { secondary } \\
\text { generalized }\end{array}$ & 2 & 32 & 55 & bedroom & supine & unknown & 7 a.m. & no & $\begin{array}{l}\text { living in the nursing home, } \\
\text { found dead at } 7 \text { a.m. }\end{array}$ \\
\hline 11 & probable & unknown & male & $\begin{array}{l}\text { focal with } \\
\text { secondary } \\
\text { generalized }\end{array}$ & 5 & 22 & 62 & bedroom & latericumbent & confirmed & night & yes & $\begin{array}{l}\text { sudden death during a seizure at } \\
\text { night }\end{array}$ \\
\hline 12 & probable & $\begin{array}{c}\text { cerebral } \\
\text { hemorrhage }\end{array}$ & male & $\begin{array}{l}\text { focal with } \\
\text { secondary } \\
\text { generalized }\end{array}$ & 4 & 53 & 67 & bedroom & latericumbent & suspected & 10 p.m. & no & $\begin{array}{l}\text { Sudden fall down with loss of } \\
\text { consciousness during walking at } \\
6 \text { p.m., and sent home. No } \\
\text { abnormal symptom or sign } \\
\text { found after wake up by doctor. } \\
\text { Sudden death at } 10 \text { p.m. }\end{array}$ \\
\hline 13 & probable & unknown & male & generalized & 3 & 37 & 67 & outside & supine & no & 4 p.m. & yes & $\begin{array}{l}\text { sudden fall down on his way to } \\
\text { work, cardiopulmonary } \\
\text { resuscitation failed }\end{array}$ \\
\hline 14 & possible & unknown & male & $\begin{array}{l}\text { focal with } \\
\text { secondary } \\
\text { generalized }\end{array}$ & 10 & 50 & 80 & bedroom & supine & unknown & 8 a.m. & no & $\begin{array}{l}\text { Living with family, found dead } \\
\text { at } 8 \text { a.m. }\end{array}$ \\
\hline
\end{tabular}




15 possible $\begin{gathered}\text { coronary } \\ \text { heart disease }\end{gathered}$ female $\begin{aligned} & \text { focal wit } \\ & \text { secondar } \\ & \text { generalize }\end{aligned}$

focal with

generalized
90

bedroom

supine

no

6 a.m.
Living with family, asked her son to give her water to drink at 2 a.m., found dead at 6 a.m. 
Table 4 Summary of incidence of SUDEP from previous community-based studies

\begin{tabular}{|c|c|c|c|c|c|c|c|c|c|}
\hline Reference & $\begin{array}{l}\text { Definition of } \\
\text { SUDEP }^{\mathrm{a}}\end{array}$ & Study site & Study design & $\begin{array}{c}\text { Median/average } \\
\text { years followed }\end{array}$ & $\begin{array}{l}\text { Sample } \\
\text { size }\end{array}$ & $\begin{array}{c}\text { Age range of } \\
\text { study } \\
\text { population at } \\
\text { baseline(years) }\end{array}$ & $\begin{array}{l}\text { Age range } \\
\text { of SUDEP } \\
\text { cases(years) }\end{array}$ & $\begin{array}{c}\text { Number of } \\
\text { SUDEP cases }\end{array}$ & $\begin{array}{l}\text { SUDEP incidence (per } \\
\text { 1,000 person-years) }\end{array}$ \\
\hline The current study & Annegers & China & prospective & 4.4 & 1,562 & $2-88$ & $20-90$ & $\begin{array}{c}\text { 15(13 probable } \\
2 \text { possible })\end{array}$ & 2.34 \\
\hline $\begin{array}{c}\text { Sillanpää, et al. }{ }^{[2]} \\
\text { (2010) }\end{array}$ & Annegers & Finland & prospective & 40 & 245 & onset age $<16$ & $4-49$ & $\begin{array}{l}\text { 18(15 with } \\
\text { autopsy) }\end{array}$ & 2.1 \\
\hline $\begin{array}{c}\text { Langan }^{[14]} \\
(1998)\end{array}$ & Other & Ireland & retrospective & 3 & 3,400 & All ages & $14-59$ & $\begin{array}{l}\text { 15(all with } \\
\text { autopsy) }\end{array}$ & 1.5 \\
\hline $\begin{array}{c}\text { Tennis,et al. }{ }^{[22]} \\
\text { (1995) }\end{array}$ & Other & Canada & retrospective & 7.83 & 3,688 & $15-49$ & NG & $\begin{array}{c}39(18 \text { definite or } \\
\text { probable, } 21 \\
\text { possible })\end{array}$ & 1.4 \\
\hline $\begin{array}{l}\text { Grønborg }^{[17]} \\
(2014)\end{array}$ & Nashef & Denmark & retrospective & 9 & 1,974 & $<18$ & $8-24$ & $\begin{array}{l}9(5 \text { with } \\
\text { autopsy })\end{array}$ & 0.8 \\
\hline
\end{tabular}




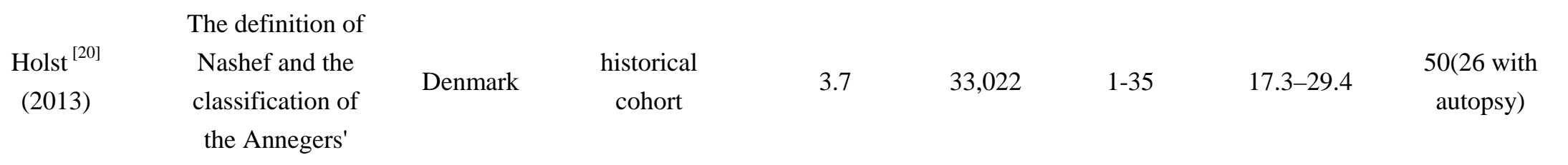

the Annegers'

Ficker,et al. ${ }^{[15]}$

(1998)

Nickels,et al. ${ }^{[11]}$

(2012)

Lahtoo,et al. ${ }^{[23]}$

(1999)
Annegers

Other

Nashef
USA retrospective

USA

prospective

7.87

UK

prospective

10

792

All ages

42

1 with autopsy

autopsy)

0.22

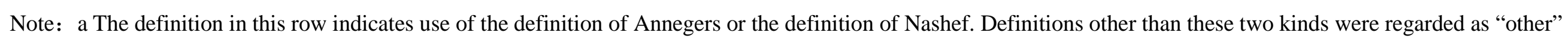


Figure 1 Flow chart of the follow-up and determination of the causes of death in the cohort with epilepsy 